\section{Progressive static pulmonary hyperinflation in survivors of severe bronchopulmonary dysplasia by mid-adulthood}

\begin{abstract}
Background: Severe bronchopulmonary dysplasia (BPD) might be associated with an accelerated age-related decline of lung function.

Methods: 14 individuals were studied longitudinally at $15 \pm 4,18 \pm 3$ and $38 \pm 3.2$ years. Information on personal history was completed, and lung function testing and skin prick testing were performed. Longitudinal data were compared intra-individually and with matched controls from the NHANES III dataset.

Results: The ratio of residual volume/total lung capacity (RV/TLC) increased markedly from $25.9 \pm 7.0 \%$ to $39.3 \pm 6.8 \%$. A significant time-effect was found compared to controls for the forced vital capacity (FVC) which decreased more rapidly than expected. Flow values were at the lower limit of normal range but remained relatively stable over time. Some individuals had completely normal lung function results.

Conclusion: Increasing static pulmonary hyperinflation with age is indicative of bronchiolar dysfunction or early emphysematous changes in survivors of severe BPD. Susceptibility for long-term sequelae shows significant variability.
\end{abstract}

In 1967, Northway et $a l^{1}$ reported on harmful effects of barotrauma and oxygen toxicity in prematurely born children, causing an acquired lung disease called bronchopulmonary dysplasia (BPD) that was characterised by patchy bronchoalveolar scarring, atelectases and overexpansion. With the introduction of lung protective ventilation and the advent of surfactant, the features of BPD have changed. ${ }^{2}$ Residual lung function abnormalities, mainly airflow obstruction and hyperinflation, ${ }^{3}$ were found in young adults, and emphysematous changes found by CT raised the question whether BPD might ultimately affect pulmonary ageing, for example, by leading to the development of chronic obstructive pulmonary disease. ${ }^{45}$

A unique cohort of 20 survivors of severe BPD born before the advent of lung protective ventilation and surfactant has been observed longitudinally into adulthood. Neonatal pulmonary management had included pressure-controlled mechanical ventilation with peak inspiratory pressures up to $40 \mathrm{~cm} \mathrm{H} \mathrm{H}_{2} \mathrm{O}$ adjusted to repeated blood gas analyses; $\mathrm{FiO}_{2}$ values of $0.3,0.4,0.75$ or 1.0 and 1 to 2 hourly suctioning and at least 48-hourly changing of the endotracheal tubes. The individuals had undergone pulmonary function testing at $15 \pm 4$ years (1983) and 18 \pm 3 years (1987). Sixteen of them could be contacted for follow-up at $38 \pm 3.2$ years, and 14 (5 women) consented to participate. Subjects underwent skin prick testing to prevalent aeroallergens and pulmonary function testing. Each individual was matched for age, sex and height with one to four individuals from the National Health and Nutrition Examination Survey III dataset, both for the 1987 and the 2008 follow-up (courtesy of Dr J.L. Hankinson, Valdosta, GA, USA). Further details are outlined in the online supplement.

The perinatal characteristics were birthweight $1795 \pm 456 \mathrm{~g}$ (mean $\pm \mathrm{SD})$, gestational

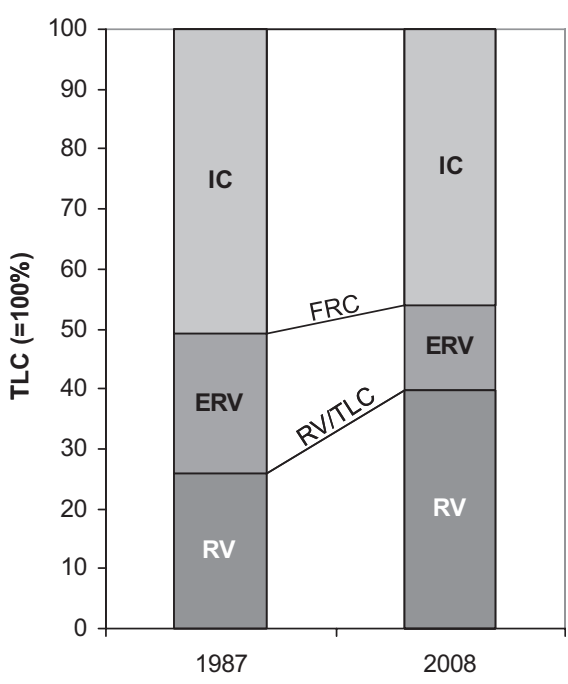

Figure 1 Stacked bar plots of static volumes in 1987 and 2008. FRC, functional residual capacity; IC, inspiratory capacity; RV, residual volume; TLC, total lung capacity. For SD, see table 1.

age $31.8 \pm 2.9$ weeks, highest documented peak inspiratory pressures $26 \pm 4.5 \mathrm{cmH}_{2} \mathrm{O}$, endotracheal intubation for 38 (range 4-103) days and $\mathrm{FiO}_{2} \geq 0.4$ for 36 (range 4-96) days. Five individuals had been tracheotomised for an extended period. The first sequential lung function study in 1983 and 1987 had revealed mean flow parameters around the lower limit of normal, but no significant changes over time.

Six individuals reported a variety of persisting respiratory symptoms, mainly

asthma, cough or shortness of breath during exercise. Four individuals with hay fever were sensitised to pollens; an additional person was sensitised to cat allergens without symptoms. Two individuals were on occasional inhaled corticosteroids. There were four current smokers (8-16 pack-years) and one former smoker. Six individuals had shown bronchial hyperreactivity to methacholine in 1987, two of whom still reacted

Table 1 Lung function data of the 14 survivors of BPD participating in both follow-up studies and shift of mean differences between patients and controls from 1987 to 2008

\begin{tabular}{llll}
\hline & $\mathbf{1 9 8 7}$ & $\mathbf{2 0 0 8}$ & p Value \\
\hline Age (years) & $18.4 \pm 3.2$ & $38.1 \pm 3.2$ & \\
BMI (kg/m $\left.{ }^{2}\right)$ & $21.0 \pm 2.8$ & $24.4 \pm 4.4$ & $<0.01$ \\
TLC (L) & $5.49 \pm 1.16$ & $7.02 \pm 1.45$ & $<0.01$ \\
TLC (\% predicted) & $96.1 \pm 12.1$ & $112.7 \pm 16.4$ & 0.04 \\
FRC (L) & $2.70 \pm 0.62$ & $3.27 \pm 0.84$ & 0.04 \\
FRC (\% predicted) & $95.2 \pm 10.7$ & $103.3 \pm 27.1$ & NS \\
RV (\%) & $108.2 \pm 26.5$ & $150.6 \pm 40.8$ & $<0.01$ \\
RV/TLC & $25.9 \pm 7.0$ & $39.3 \pm 6.8$ & $<0.01$ \\
FEV ${ }_{1}$ (L/sec) & $3.10 \pm 0.8$ & $2.95 \pm 0.88$ & NS \\
FEV 1 (z-score) & $-1.8 \pm 1.7$ & $-1.8 \pm 1.2$ & NS \\
FVC (L) & $4.15 \pm 1.01$ & $4.1 \pm 1.15$ & NS \\
FVC (z-score) & $-1.2 \pm 1.2$ & $-1.7 \pm 1.3$ & NS \\
FEV $/$ FVC (\%) & $72.6 \pm 9.1$ & $69.9 \pm 9.9$ & NS \\
FEV $/$ FVC (z-score) & $-1.7 \pm 0.8$ & $-1.3 \pm 0.9$ & NS \\
MEF50 (L/min) & $2.98 \pm 0.91$ & $2.70 \pm 1.03$ & NS \\
MEF50 (z-score) & $-1.61 \pm 1.02$ & $-1.46 \pm 0.77$ & NS \\
MEF25 (L/min) & $1.48 \pm 0.77$ & $1.19 \pm 0.70$ & NS \\
MEF25 (z-score) & $-1.27 \pm 0.98$ & $-0.93 \pm 0.61$ & NS \\
\hline
\end{tabular}

\begin{tabular}{|c|c|c|c|}
\hline & $\begin{array}{l}\text { Shift of mean } \\
\text { difference } 1987-2008\end{array}$ & $95 \% \mathrm{CI}$ & p Value \\
\hline FVC (L) & -0.584 & -1.092 to -0.076 & 0.03 \\
\hline $\mathrm{FEV}_{1}(\mathrm{~L} / \mathrm{sec})$ & -0.367 & -0.971 to 0.237 & NS \\
\hline $\mathrm{FEV}_{1} / \mathrm{FVC}$ & 0.003 & -0.138 to 0.143 & NS \\
\hline
\end{tabular}

Numbers indicate means \pm SD.

$\mathrm{FEV}_{1}$, forced expiratory volume in the first second; FRC, functional residual capacity; FVC, forced vital capacity; MEF25, 50, maximum expiratory flows at $25 \%$ and $50 \%$ of vital capacity; RV, residual volume; TLC, total lung capacity. 
in 2008. One originally negative person showed moderate reactivity in 2008. Transfer factor of the lung for carbon monoxide in 2008 was $83.5 \pm 15.7 \%$ (mean $\pm S D$, range $58-107 \%$ ) of predicted; FeNO was $10.8 \pm 8.5$ (range 4-27 ppb). The results of pulmonary function testing are depicted in table 1 and figure 1. Smoking and other potential confounders had no significant effect; lowest flow values were found among non-smokers.

The results are consistent with a progressive static hyperinflation into mid-adulthood, suggestive of progressive bronchiolar dysfunction or early emphysematous changes with ageing in severe BPD. The relatively minor flow changes during the 20-year period indicate dysfunction of small airways and are dissimilar to chronic obstructive pulmonary disease, hinting to differing disease mechanisms. The current study is in line with the concept of adult lung disease originating early in life. Susceptibility for long-term sequelae shows significant variability.

Acknowledgements We are indebted to Christian Schindler, Swiss Tropical and Public Health Institute, Basel, for his invaluable help with the statistical analyses. We are deeply grateful to Philip H. Quanier, Erasmus MC, Rotterdam, for his prompt and fruitful assistance with standardisation of lung function data and for enabling the matching with controls from the National Health and Nutrition Examination Survey III cohort. We would also like to thank John L. Hankinson, Valdosta, GA, USA, for providing the data of matched controls from the National Health and Nutrition Examination Survey III cohort.

\section{Daniel Trachsel, ${ }^{1}$ Martin H Brutsche ${ }^{2}$} Henriette Hug-Batschelet, ${ }^{1}$ Jürg Hammer ${ }^{1}$

${ }^{1}$ Division of Paediatric Intensive Care and Pulmonology, University Children's Hospital Basel, Basel, Switzerland; ${ }^{2}$ Division of Pulmonary Medicine, Canton Hospital,

St. Gallen, Switzerland

Correspondence to Dr Daniel Trachsel, Division of Paediatric Intensive Care and Pulmonology, University Children's Hospital Basel, Postal Box CH-4005, Basel, Switzerland; daniel.trachsel@ukbb.ch

- An additional material is published online only. To view this file please visit the journal online (http://thorax.bmj. com/content/67/8.toc).

Funding The study was supported by a grant of AstraZeneca, Switzerland.

\section{Competing interests None.}

Ethics approval This study was conducted with the approval of the Ethics Committee of Basel (ref. no. 338/07).

Contributors DT was primary investigator in all aspects of the study. MHB significantly contributed to the design of the study and interpretation of results from the adult pulmonologist's perspective. HH-B was primary investigator of the first follow-up study and added to the manuscript. JH helped with the design, the execution and the analysis of the study and writing the manuscript.

Provenance and peer review Not commissioned; externally peer reviewed.

Accepted 26 July 2011

Published Online First 25 August 2011

Thorax 2012;67:747-748

doi:10.1136/thoraxjnl-2011-200695

\section{REFERENCES}

1. Northway WH Jr, Rosan RC, Porter DY. Pulmonary disease following respirator therapy of hyalinemembrane disease. N Engl J Med 1967;276:357-68.

2. Husain AN, Siddiqui NH, Stocker JT. Pathology of arrested acinar development in postsurfactant bronchopulmonary dysplasia. Hum Pathol 1998:29:710-17.

3. Northway WH Jr, Moss RB, Carlisle KB, et al. Late pulmonary sequelae of bronchopulmonary dysplasia. N Engl J Med 1990;323:1793-9.

4. Filippone M, Carraro S, Baraldi E. From BPD to COPD? The hypothesis is intriguing but we lack lung pathology data in humans. Eur Respir J 2010;35:1419-20.

5. Wong PM, Lees AN, Louw J, et al. Emphysema in young adult survivors of moderate-to-severe bronchopulmonary dysplasia. Eur Respir J 2008;32:321-8. 